\title{
第一个人造太阳卫星
}

\section{B. 彼待罗維奇}

1959 年 1 月 2 日莫斯科时婔晚 8 点布右, 苏联发 射了一支强大的宇宙火筒。赤热的燃燒产物以每秒几 公里的速度从发动机裝置的缶咀噴射出来, 它們照亮 了整个視野內复盖着白雪的大地和被烏云掩蔽 的天 空, 明党得就像白蓄一样。在一大团濃厚的烟尘的发 射地点, 自地面騰空升起了水蒸气和雲尘。在发射 宇宙火箱的鹰术般的画景中, 还件随有功率能达到 数百万匹馬力的发动机裝置发怙的难以遏止的怒吼 声。

这一多級火简汌足丁速度，具有充分把握地垂直 发射了上去, 随后又从容不迫地飞入了預定的軌道。 在人类历史上，苏联宇宙火筒第一次达到挑超过了第 二宇宙速度，火箭在超过这一速变之后，最后一級的 发动裝置垖停止了工作。重量为一肿本(在然料储备 用完以后净溗 1,472 公斤)的火筒最后一級,完全克服 了地心引力，扭沿着双曲綫軌道往月球方向飞去，存 发射后 34 小时,它到达了距月球最近的一点 $(5,000$ 6,000 公里), 打作为太阳的卫尾, 我們太阳系的 新 行星, 进入了自己永久繞太阳运行的枝盾形軌道。

在从宇宙火符发射日起到其进入自己的永久軌道 为止的这一期閉內，通过无綫电广播和报紙发表了塔 斯社的 13 次报导，在报导中确定了火箭經过的路綫， 扭顶报了它以后的运行情况，同时还指出了这一具有 历史意义的飞行是最偉大的事件。

1957 年 10 月 4 日全人类庆呒了自己第一次克服 地心引力束緷的胜利, 師苏联火箭达到了保証发射人 造地球卫星的第一宇宙速度。1957 年 11 月 3 日和 1958 年 5 月 15 日, 苏联人民的天才又建立了更重和 飞得更高的人造地球卫星一一宇宙 实驗室。1959 年 1 月 2 日全人类又庆祝了塋破地心引力束縛的第二次 彻底的胜利，苏联火䈤达到讲超过了第二宇宙速度。 这样也就使得火箭可以永久眖离地球, 未在圍繞太阳 运行的大小行星中佔据了自己的位置。

苏联的宇宙飞船首先开始了星际飞行，抖沿着与 地球軌道交叉, 与火星玌道最近点距离 1,500 万公里 左右(較地球与火星間的最大距离大約小四分之三)的 軌道运行，根据計算，宇宙火箭运行軌道的坟㡖与地
球运行軌道的長軸大約成 $15^{\circ}$ 角, 火简运行軌道对地 球軌道平面所成的傾角仅仅是 $1^{\circ}$ 左右。火箭圈繞太阳 运轉的軌道偏心率是相当大的（等于 0.148 )。人造行 星的近日点距太阳是 14,600 万公厘(大約比地球的近 日点近 100 万公里), 远日点距太阳是 19,700 万公里! (大約比地球的远日点远 4,500 万公里)。它圍緮太阳 运轉的周期是 450 个地球日（也就是 15 个月 左右）, 囯纘太阳运行的最大速度是每秒 32.5 公里, 最低速 度是每秒 23.7 公里。

火箭和地球在圍繞太阳运轉时，它們之润的坟人 距离將达到三亿到三亿五千万公里。它們之聞的歇小 距离將会达到极小的程度，但是它們近到相遇的可能 性是非常小的。

宇宙火箭的运行，使得比以前任何时候都更有汀 能在距离地球很沅的空間对星际介質进行复杂的綜合

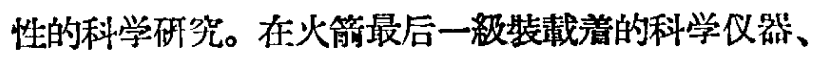
測量仪器連同容器和能源坟置的总重量, 訫为 361.3 公斤。

火箭上装置的各种仪器設备, 保䃌可以进行下列 研究: 宇宙綫的强度和强度变化、宇宙戟中的光子、 原始宇宙綫中的重核、流量微粒、行星际物筫的气，体 組分和太阳微粒幅射、磁㘯、容器內的溫度和底力, 火 箭运行軌道的确定和预报、人造鈴云慧星的制造等。

火简最后一級中装置的无綫电发射机，以19.993、 19.995、19、997 和 183.6 兆周的頻率发射信号, 这样 就保証了与地面的联系和发揆必要的情报。

由于科学仪器的正常工作, 从而获得了更要的絬 果，这些秸果今后將边整理边公布。

为了发射重量由 1 吨牛的太阳卫星, 使用了完善 而强大的彈道火箭。用这种火箭可以发射任何种用途 的、重达很多吨的地球卫星, 或把重量更大的物体发 射到地球的任何一点。

这种完羓的火筒的特点, 在于它的結棈有高庭的 重量效能和裴备有高效率的强大的发动机, 裴备有保

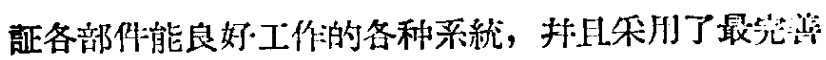
的火箭飞行的稳等系統和操緂系䋁。

苏联火筒的順利飞行不是在屡次发射失账话況下 
的唯一的和偶然的成就，而是有訃划地系総地研究火 箭構造的結果。荡联火简不停歇地在舡先規定官的时開 队发射州去了, 抹严格地沿着事先設計的制道在运 行。

宇宙火箭在星际室開的飞行，标志着苏联在全面 发展火箱技术的基础上，在研究与学握宇宙的事前 中，合乎逯輯地前进了一步。近程火筒、洲內火箭、 洲际火箭、地球卫星和最近发射的太阳卫星一一这就 是我們經历的道路。

苏联的彈道火箭是为和平事淥、科学进步、認識 宇宙和征服字宙服务的。但是这些火简迎提卫着我們 的社会主义祖国，准备着給予对我国和与我国签訂有 互相帮助和共同防御条的的社会主义陣营其他国家进 行侵犯的任何侵略荅以毁灭性的打击。但是我們也相 信和平的力量一定会战胜, 人类他將永远不会道到核 子战争的焂难。

为苏联增加光尔的火筒制造業方面的成就，尽管 是如此的点著辉煌, 但所走过的路程也只是人类任进 一步发展中所要嗱循的偉大道路的开端出。

現在可以明显地番出，在今后的若干年中，在研 究和掌握宇宙方面, 火箭技术的发展將导向三个基本 方向，这三个方向將同时进行研究。

第一个方向是关于建造一系列不同重量和不同用 途的人造地球卫星, 首先就要建造几批能保証对整个 地球表面和地球周圍大气图进行經常性观测的卫星, 这些卫星要装备有进行覌测所必需的全套科学仪器, 其中包括光学仪器和傳溳設备。

这些卫屋对增加我們关于地球及其周園宇宙室間 的知識来說, 意义是非常巨大的。当然, 这些覌測用 卫星的軌道本面将与地球赤道成很大的角度, 以便能 娊湘到地球的整个表面。

將要探討使整个卫星或是卫尾的重要部分在地球 上安全自动降落的問題，隆落过程基本上是依素大气 的阻力, 可以利用支承表面(滑叛降落), 也可以不利 用支承表面。在完成了装有仪器的容器, 然后是裝有 功物的容器的安全降落之后, 就該是人剩清能返回地 球的人造卫星进行飞行了。

这一方向的进一步发㕍，將会建造情青管没备

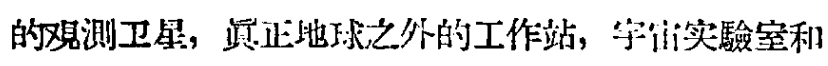
天文台。將来，这些工作站将在帮助守拄火简进行行 星际飞行方面完成新的职能。

人造卫星离地球泣面的平均高度將根据卫星的用

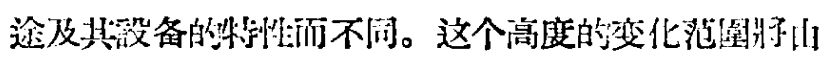

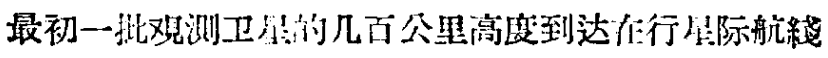

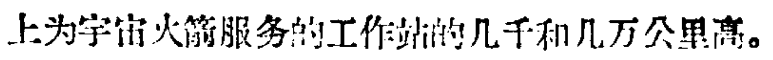

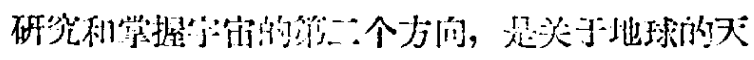

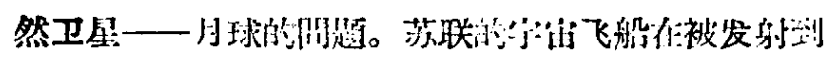
軌道上沓的时候, 經过了离月球裴面昰近的地力, 其 距离比从地球到月球的距离小 70 倍。这次飞行只浣 定了研究离我們最近的天体一月球的开端。今后的 飞行將使得有可能完成繞月球的飞行，在飞行过程中 拍照月球的背面，井在火箭的归途中將咉象发途到地 球上来。建立一个与地球保持永久无綫电联系的人造 月球卫星是必要的。

在月球火箭的飞行过程中, 將对距地球五千公里 范圍內的宇宙空阴及其中发生的全部现象进行詳緗的 研究。

正像济联宇宙火筒成功的飞行所証实的那样, 有

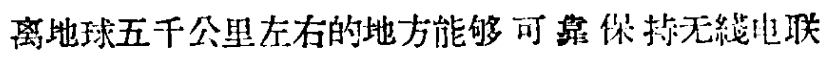
系, 㚘目現在我們知道, 距离哃远得多山能进行无䋐 电联系。

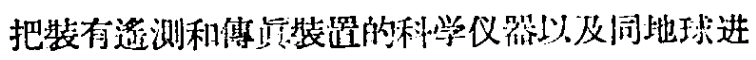

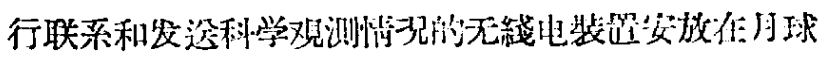
表面上, 可以大大地扩大㳔月球的研究。要做到这一 点, 需要解决使裝有仪器的行器在月球上:安全降落的 問題。

由于在月球上触乏, 具有实际意义的数量似空气， 所以需要利用火籍最后一級的火籍发动机, 或是利用

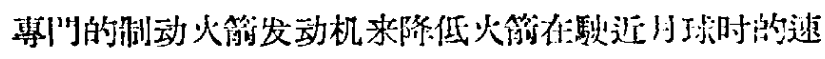

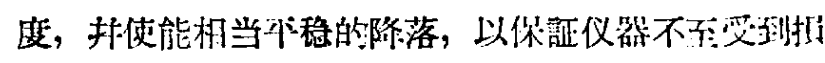
坏。要完成这种飞行, 月球火籍开始㴗与!有接近第;

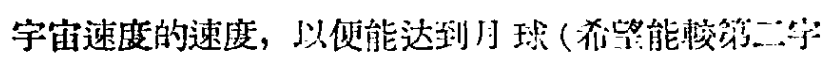

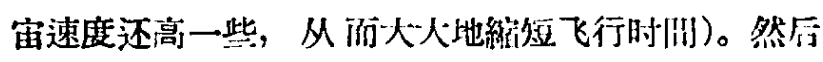

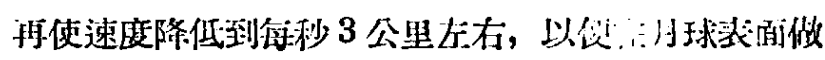
无冲古降落。因此, 要使到月球的飞行, 在隆落时火 管与月球表面相遇的速度等于管, 就要給火简大的相 当于每秒 14.5 公里的总速度。

用逢測的方法对月球表面性䝿的研究不能对科学 界所关心的全部閣題給以非尽的回签。关于月球牢不

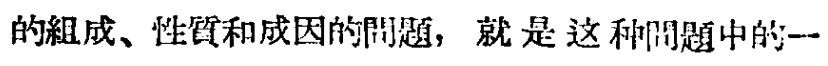
个。因而实現載人的火籍飞行是合乎摆㡐的，也是不 可避免的。对月球表面結構的研究，以及利川火箱项

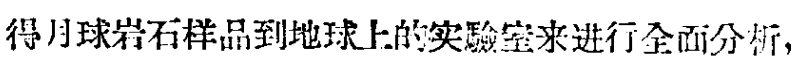

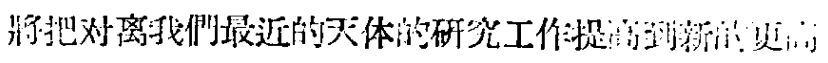

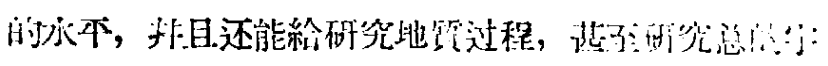

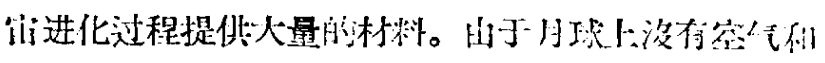

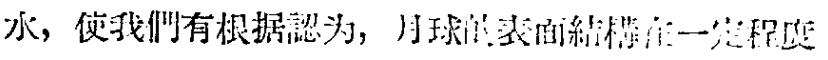

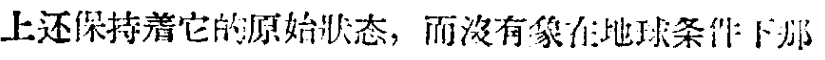


样受水、风和冰川的作用而发生后成层理。

积累使裝有自动科学仪器的重型容器位归上安 全降落的經驗, 以及月这些仪器研究月球上的主要条 件，將有助于积瑟实現人类飞往月球所必需的资料。

單独发射一个载人的、能降落到月球上又能返回

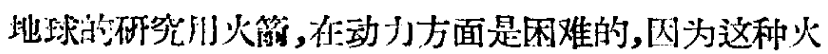

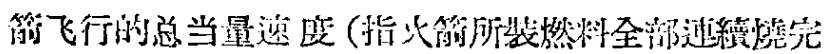

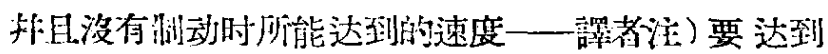

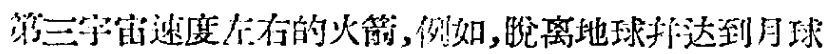
要 11.2 公黑/秒，向月球降落时要减速 3.3 公里/秒， 从月球起飞返回地球㱯 2.4 公里/秒; 剩余的速度在 问地球降落的过程中受大气阻力而消失。括版上大箱 上为校正飞行 (其中包括在返回能球时的飞行标准) 所必需的补光能量储备, 因而需要的最低总当量速度 將要稍大于 17 公里/秒。

載人的飞行山可以利用功杽較小的火简来实現。 为此, 黒要猚先问月球发射几个容器 (要能无冲击地 降落到月球上), 这些容器们装有必要的燃料儲备, 以 便任返回地球之前給灾箭添加燃料。

在这种情况下，火简在从地球起飞时只储备能仗 火简最后一級到达月球, 抹能安全地降落到月球上所

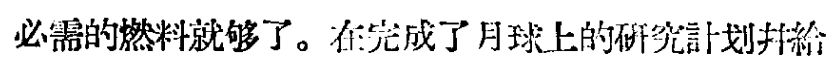
大箭的最后一級添加了用容器运齿的燃料之后, 考察 队就可以順利地返回地球。

鉴于实現人类宇宙飞行的复杂性, 为了罾加茗祭 队的安全, 可能会同时发射网两个月球火箱, 因为这 样, 在回来们起程准备过程中网組飞行人员可以互棑 帮助, 排且位洞个火箭当中有一个发生故院不能修复 时, 兩組飞行人员可以乘一个火箭回来。

无疑，在笑現人在月球上降落的飞行之箭，蔣先 要进行人能隆落到地球上:来的繞月球飞行, 因为后者 在动力方面比较容易达到, 做起来也比較简單一些, 同时这种飞行他能进行大量的科学研究。

研究和掌握宇宙的第三人方向, 是划我椚太阳系 行星的研究。目前可以进行宇宙探测火節飞往离我們 最近的行星一一火星和金星的准备工作。1959年 1 月 2 日发射的、經过月球附近飞向火星軌道的苏联宇 宙火笪的第一次行星际飞行証明了，住现代火简技术 的发展情况下，飞往火是和金星在动力方面是完全可 以做到的。

最初几次行星际飞行的目的是最大限度地接近所 研究的行星, 以研究它們的性领, 然实当守宙火简返 回到与地球接近时將覌测的結果发射到地球。

行星际飞行將是漫長的, 就是飞徍最近的行星再

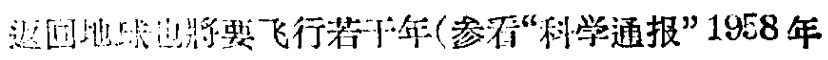

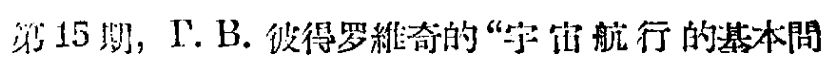

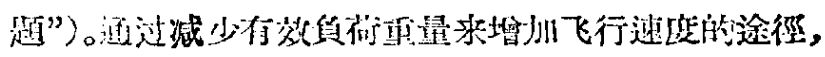
订以人人地綰短飞行时活，可是这种办法将会降低飞 行武雅的科学纵值。

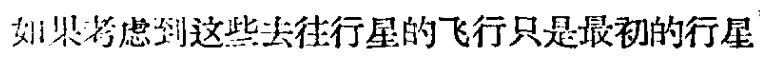

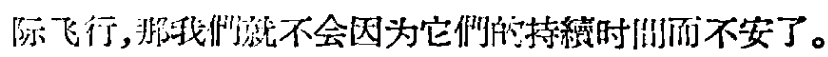
个店，火簡找术的次展，而且主要是，所川能源較現

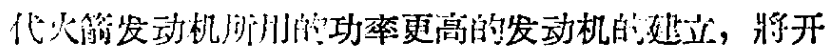

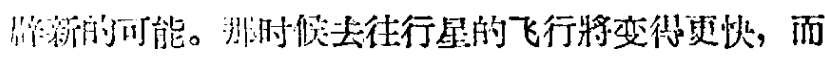
洗摆合理济起程时開会較目前容易。

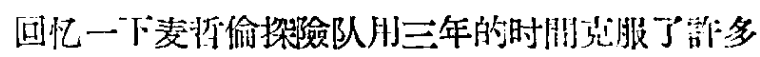
休难完成的第;一次环球旅行是有好处的。相: : 一世紀

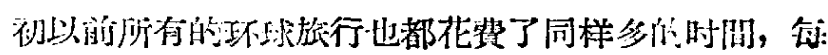

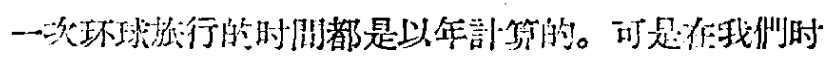

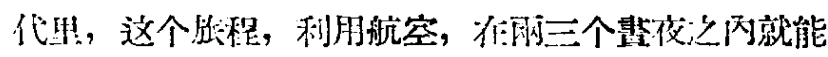

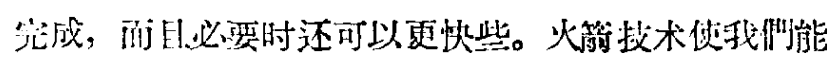

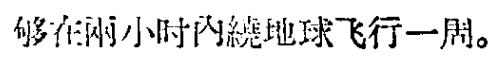

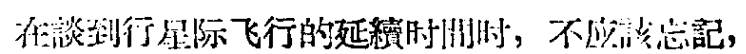
这些飞行路嘎琴接达几亿和几十亿公里。

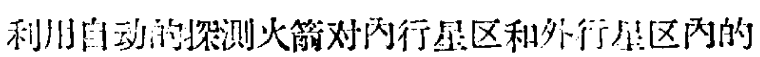

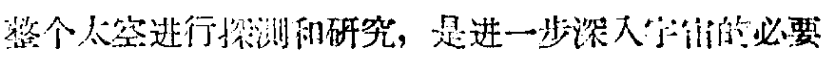

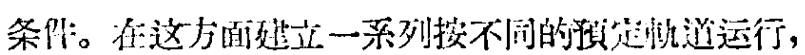
装有仪器和等太阳电池供电的永久无綫电古的人浩太

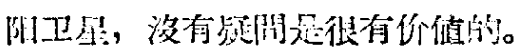

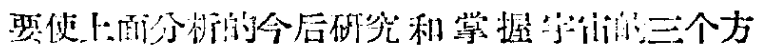

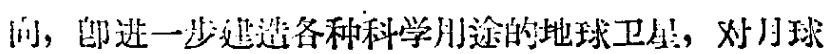
的研究，实现行星际飞行和进一步建造太阳卫屡等， 都得到充分的发展，首先就要求不断地革新火简技术 和趛造起始重量更大、效率更高的火简，而这一点只

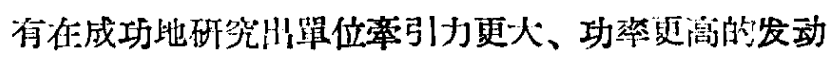
机裴语的条俳下手是可能的。此外，还应該改进火简

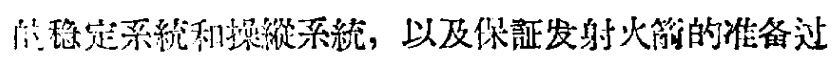

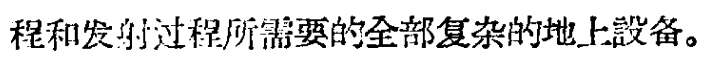

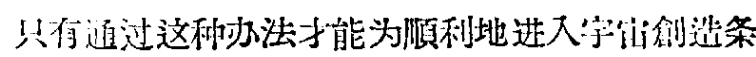

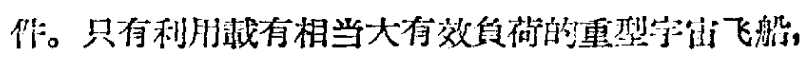

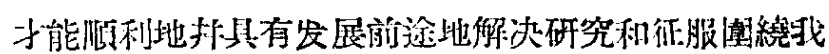
荫的守官空阿的任务。

要实現建立地球卫只、月球火筒、星际飞船和太

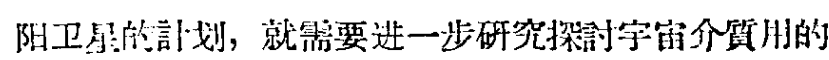
各种科学仪器和改进具有高分辫能力的多道遥测无䄉 电裝留，以倾把覌测粘果从远达几百万公里以外的地 方农这到地面上来。

应核拟大宇宙医学方面的研究范圍, 因为对这川 
学科的問題的研究將要用具体現笑的方案来完成的时 刻迫近了。

上迌这項㨁接进入宇宙的計划, 实际上在前一世 紀末和本世紀初就已被 K. A. 齐奧尔科夫斯基提汕 了。齐奥尔科夫斯基的經典著作具有非常广闊的見解 和惊人的果敢精神，敍迅了运用宇宙間天体的多样性 去始柊不渝地研究宇宙空間和使宇宙空間住滿人的道 路。

从事于这一問題研究的苏联科学家和設計师們， 都是齐奥尔科夫斯基的学生 和他的偉大事業的秋氺 人。我們仅仅是进入到齐奧尔科夫斯基所指出的进入 我何㸝圍的无限的宇宙空间的偉大道路的开始阶段。 而这条道路是没有止境的, 正象人类进步的道路是没 有止境的一样。

为了認識字'解这种合人愉快的工作，为了人类的 袺利，吘多苏联科学家、設計师和技术人員將自己的 一生献給了征服宇宙的偉大事業。他們为自己能生活 非劳动任苏維埃国家而感到幸鲨, 因为这个国家給他 們提低了我国高度发展的社会主义科学和工業的一切 可能条件，来实現人类早在发展初期就已䤊酿着的非 常奥妙栭又大胆的意愿。

我們为自己能生活和劳劝在㼛会主义国家而感到 幸稿㝵, 囚为这个国家的領导者的一切意图, 都在于保 卫我們地球和地球以外的和平，在于以劳动人民自己
的劳动来败善他們的物質福利。

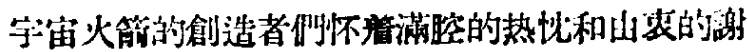

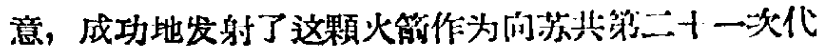

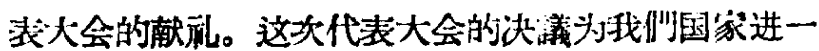
步走向幸福和富强鋪本了道路，世铺平了为我們美好 的地球上的各国人民的和平和龙誼的阳光所照䠛的道 路。

保证創造和发射这顆宇宙火箭的科学研究所、殷 計局、工厂和蹗驗單位的工作人員，都怀着极其兴奋 的心情領会到赫魯曉夫同志在苏共第二十一次代表大 会上发言以及他代表党和苏联人民问他們所作的热烈 的賀詞。

为了回答党和人民的謝意和来自地球各个件落的 无数的祝賀，火箭的刢造者一科学家、曹家和工人們

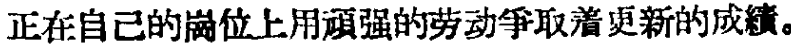

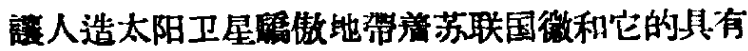
紀念意义的誕生日期的标記，去遊历完自己下一步的 光荣的旅程吧!

来来的宇宙旅行箸进入世界上第一个人造行星的 轨道，赶上这顆行尾，記下它上面的标記，找把自己 所能做到的一切献給以全人类的法福作为自己的旗帜 的苏維埃国芜，这一时刻定將到来。

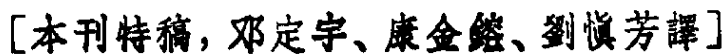

\section{等离子区射流发生器 范 艮藻 (中国科学院力学研先而)}

随着韻气拔术的发展，人們对上万度以上的高溫 气流兴诹急来会大。一方面，室气动力学家和物理学家 硼究着在超高声速飞体表面的那 层 溫度在 $10,000^{\circ} \mathrm{K}$ 以上的裁热气流中究䆓发生了哪些物理的和化学的过 程，以及这些过程对飞体的方影响; 另一方面，冶金 学家和工程师叉在努力寻找酎高溫的合金材料, 以防 止飞体的焚斟、过热，扞保持足够的剛度与强度。

这些研究应核說多牛是以实驗的方法来进行的。 因此怎样能在实驗室內产生 $10,000^{\circ} \mathrm{K}$ 以上的高溫源 就成为一个迫切需要解决的問题。然离子区射流发生

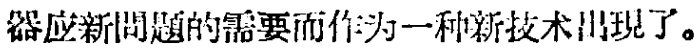

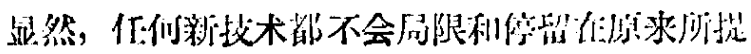

队的問題上。等离子区射流发生器也是这样：它一方 面对工程技束提化了新的有力的工，具，问时世开拓了 敌多新的科学找术问域。对科找工作等来满就是怎样

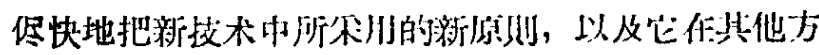
面应用的订能性吸收到工作中㫖。为此任卜泊將介释 一下离子区射流发生器的工作江理!、技术条作，以 及它任工程技术上的应㺫。

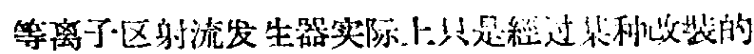

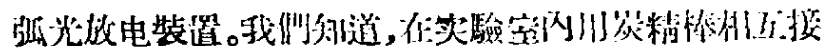

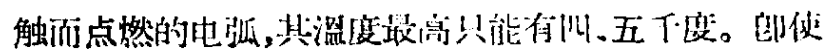

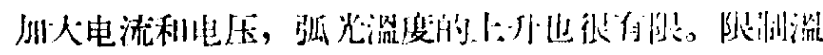

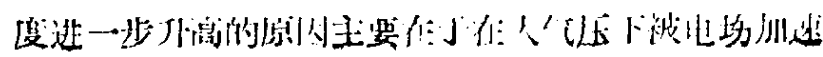

